\title{
As favelas cariocas nas chanchadas: de berço do samba a problema público ${ }^{1}$
}

\section{The Rio's favelas in musical comedy films: from cradle of samba to public problem}

Rafael de Luna Freire ${ }^{2}$

Leticia de Luna Freire ${ }^{3}$

Resumo: Este artigo traça um panorama histórico da representação das favelas cariocas nas comédias musicais cinematográficas brasileiras, conhecidas como chanchadas, dos anos 1930 ao início da década de 1960. Com raras exceções, como a do filme Favela dos meus amores (1935), apontamos a presença mais constante da favela como cenário reproduzido em estúdio em números musicais das chanchadas lançadas até meados dos anos 1950. Tomando como marco o filme Depois eu conto (1956), a representação da favela passa a ser cada vez mais politizada no gênero. Em meio às polêmicas sobre as remoções das favelas e a atuação social da Igreja católica na transformação desse tipo de habitação popular em "problema público", analisamos Três colegas de batina (1961), em que uma favela adquire grande importância na trama, mas com um discurso ideológico distinto dos mais conhecidos filmes dos diretores do Cinema Novo.

Palavras-chave: chanchada; favela; Igreja; samba; cinema.

Abstract: This article traces a historical panorama of the representation of Rio's favelas in Brazilian musical comedy films, known as chanchadas, from the 1930s to the early 1960s. With rare exceptions like that of the film Favela dos meus

l Uma versão preliminar deste trabalho foi apresentada na I Jornada de Estudos em História do Cinema Brasileiro, que teve lugar no Instituto de Arte e Comunicação Social da Universidade Federal Fluminense em agosto de 2017.

2 Universidade Federal Fluminense. Niterói, RJ, Brasil. https://orcid.org/0000-0002-4739-0603 E-mail: rafaeldeluna@hotmail.com

3 Universidade do Estado do Rio de Janeiro. Rio de Janeiro, RJ, Brasil. https://orcid.org/0000-0003-3762-3386 E-mail: leluna2005@yahoo.com.br 
amores (1935), we point to the more constant presence of the favela as a setting staged in the studios in musical numbers of films released until the mid-1950s. Taking as a milestone the film Depois eu conto (1956), the favela representation is increasingly politicized in the genre until the end of the decade. In the context of polemics about the removal of favelas and the social activity of Catholic Church in transforming this type of popular housing into a "public problem", we analyse Três colegas de batina (1961), in which a favela acquire great importance for its plot, but with an ideological discourse distinct from the best-known films of the Cinema Novo movement.

Keywords: chanchada; favela; church; samba; cinema. 


\section{Introdução}

Este artigo traça um panorama histórico da representação das favelas cariocas nas comédias musicais cinematográficas brasileiras, conhecidas como chanchadas, dos anos 1930 ao início da década de 1960. Estamos cientes de possíveis limitações metodológicas nos estudos de representação no cinema, como o risco de essencialismo ou da exigência moralista por imagens positivas (STAM, 2003, p. 303-304). Em nosso caso, buscamos um olhar atento ao cinema como criação artística, mas também como prática social e historicamente localizada. Evitando um a-historicismo ao analisar as diferentes formas como as favelas foram retratadas num amplo conjunto de filmes brasileiros realizados ao longo de três décadas, atentamos para as instabilidades históricas das representações e para as diversas vozes em jogo. Como indica Robert Stam (2003, p. 305): "Não basta dizer que a arte é construída. Temos de perguntar: construída para quem e em conjunção com quais ideologias e discursos?”.

Nessa trajetória, o ponto de partida é apontar como a favela foi abordada pelo cinema brasileiro, em geral, e pelas chanchadas, especificamente, por meio de realizadores que não pertenciam àquelas comunidades. Mas mesmo nesses filmes, marcados por um olhar de fora, há diferenças significativas, ainda que também seja possível apontar padrões e tendências. Assim, com poucas exceções, como a do filme Favela dos meus amores (1935), apontamos a presença mais constante da favela como cenário reproduzido em estúdio em números musicais das chanchadas lançadas até meados dos anos 1950. Tomando como marco o filme Depois eu conto (1956), indicamos a alteração na representação da favela, que passa a ser cada vez mais politizada no gênero. Em meio às polêmicas sobre as remoções das favelas e a atuação social da Igreja católica na transformação desse tipo de habitação popular em "problema público", analisamos mais detalhadamente, ao final do artigo, Três colegas de batina (1961). Nessa chanchada, uma favela adquire grande importância 
na trama, mas com um discurso ideológico distinto dos mais conhecidos filmes dos diretores do Cinema Novo realizados na mesma época. ${ }^{4}$

\section{A favela como berço do samba}

Na década de 1930, com a consolidação do cinema sonoro, a produção cinematográfica ficcional brasileira ficou, em grande parte, confinada ao interior dos estúdios de cinema, concentrados no Rio de Janeiro, por questões técnicas, estéticas e econômicas, diminuindo radicalmente o número de cenas filmadas em locações externas (FREIRE, 2016). Além disso, a novidade da voz, dos ruídos e da música sincronizada às imagens levou à popularização dos filmes musicais carnavalescos - posteriormente conhecidos como chanchadas -, que exploravam o sucesso comercial crescente da música popular em meio ao vigoroso desenvolvimento da indústria fonográfica e radiofônica.

Os filmes musicais produzidos pelos principais estúdios cariocas da época priorizavam a filmagem em interiores recriados em estúdio, mas uma produção em particular buscou filmar cenas em locações reais numa favela. Mesmo retratada de forma mais realista em Favela dos meus amores (Humberto Mauro, 1935), como nos demais filmes da época, as favelas eram basicamente associadas ao samba, gênero musical de crescente sucesso comercial.

Favela dos meus amores infelizmente integra o rol dos filmes brasileiros desaparecidos, tendo sido mitificado por historiadores como Alex Viany como uma pioneira obra de realismo crítico a partir de idealizações a respeito da filmagem em locações reais na favela da Providência, na área central da cidade, e de sua trama, que defendia os morros cariocas como berço autêntico do samba (seu título provisório era Alma

4 Ao confrontar a representação da favela no cinema brasileiro contemporâneo com a de filmes dos anos 1950 e 1960, a pesquisadora Ivana Bentes (2007, p. 203) praticamente restringe sua comparação a obras do Cinema Novo e à produção francesa Orfeu no Carnaval (Marcel Camus, 1959), afirmando que "as chanchadas exploravam as áreas nobres do Rio de Janeiro: o Copacabana Palace, o Quitandinha, as boates e espaços considerados chiques, territórios da crônica social". Este artigo pretende evidenciar que essa é uma visão simplista sobre o gênero. 
do samba). Entretanto, analisando documentos do filme em atenção ao contexto cinematográfico da época, podemos afirmar que Favela dos meus amores era um romance musicado que não se diferenciava tanto assim de filmes contemporâneos que, felizmente, sobreviveram, tais como Bonequinha de seda (Oduvaldo Viana, 1936) ou Maridinho de luxo (Luiz de Barros, 1938), com seus cenários luxuosos, mise-en-scène de estúdio e pretensão a superprodução (Figura 1).

Figura 1 - Mayer e Costa em Favela dos meus amores.

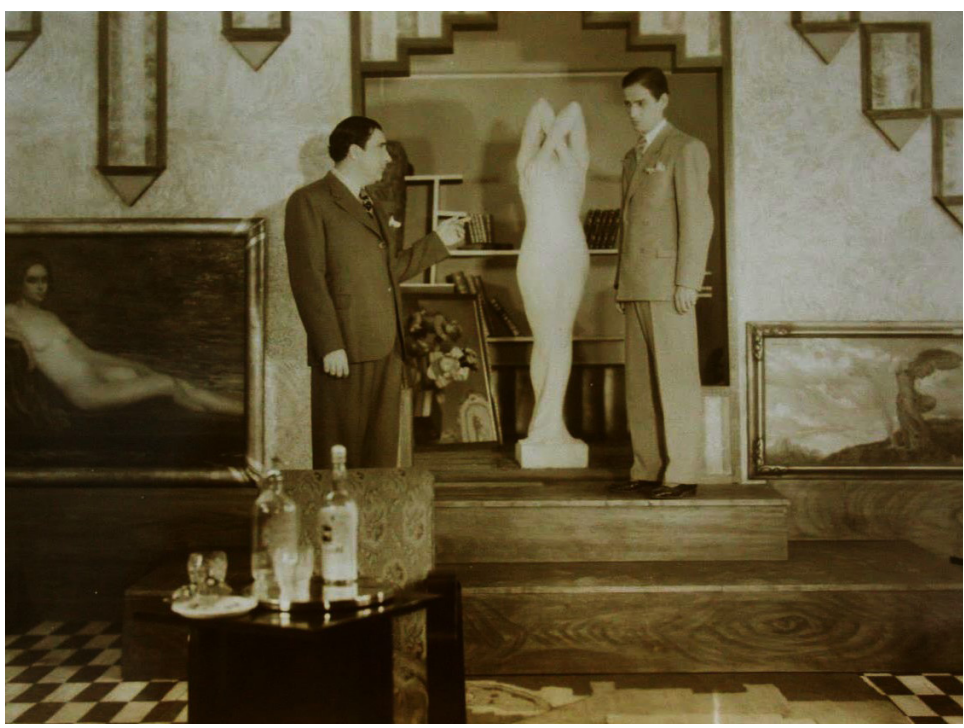

Fonte: Arquivo Geral da Cidade do Rio de Janeiro (AGCRJ).

A história do filme de Humberto Mauro girava em torno de dois amigos "boas-vidas" interpretados por Jayme Costa e Rodolfo Mayer. Recém-chegados de Paris, mas sem um tostão no bolso, a dupla decidia abrir uma boate na favela, apelando para o exotismo como compensação para a ausência de luxo. No pitoresco cenário da favela, o personagem de

5 Hernani Heffner (2007) apontou como Alex Viany destacou a suposta força e autenticidade no uso da locação em sequências de filmes como o próprio Favela dos meus amores, percebendo essa prática como um desvio em relação à tendência dominante do estúdio. Na esteira de Viany, Napolitano (2009) indagou se Favela dos meus amores faria parte de uma possível tradição dentro da chanchada - tradição abortada, em sua opinião - marcada por um realismo crítico e certo discurso sobre questões sociais que chegariam aos filmes de Nelson Pereira dos Santos nos anos 1950. 
Rodolfo Mayer se apaixonava por Rosinha, uma ingênua professorinha do morro interpretada pela estrela e produtora do filme Carmen Santos.

A partir de fotografias de cena de Favela dos meus amores, podemos perceber que a "casinha" na favela da personagem Rosinha era reproduzida em estúdio e, tanto por fora quanto por dentro, parecia bem diferente dos barracos de madeira usuais nas favelas da época, sendo modesta muito mais por comparação com os demais espaços luxuosos do filme por onde os personagens transitavam (Figuras 2 e 3). Como cenário para cenas dialogadas, naturalmente, a casa da personagem dificilmente seria filmada em locação por motivos técnicos. Além disso, não era o perfil de Carmen Santos, como atriz e produtora, tematizar pobreza ou miséria em seus filmes. A atriz seria criticada, inclusive, por sua personagem Rosinha usar, de forma inverossímil, "vestidos de alto preço e joias de custo elevado" mesmo sendo apenas "uma professorinha do morro” (NAPOLITANO, 2009, p. 149-150; FREIRE, 2011, p. 269-270).

Figura 2 - Favela dos meus amores.

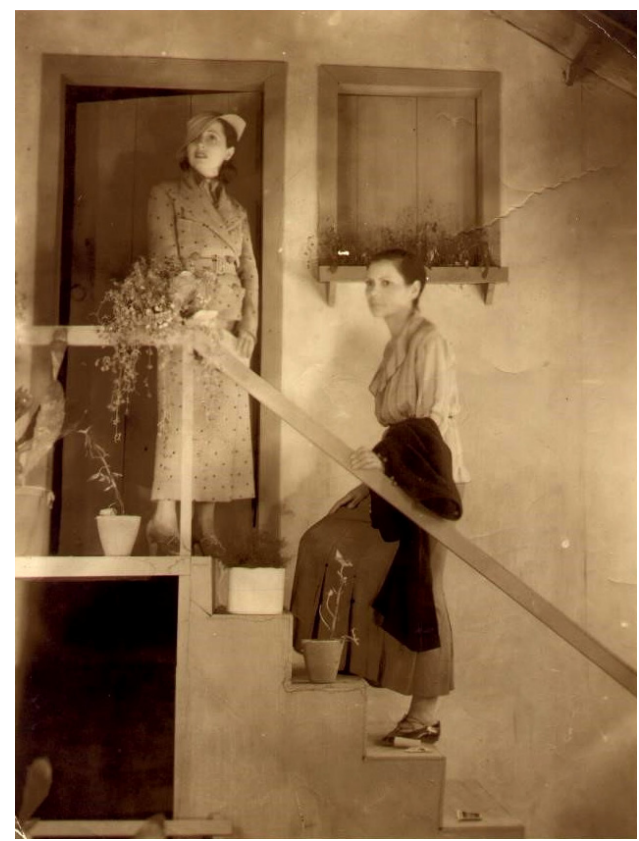

Fonte: AGCRJ. 
Figura 3 - Favela dos meus amores.

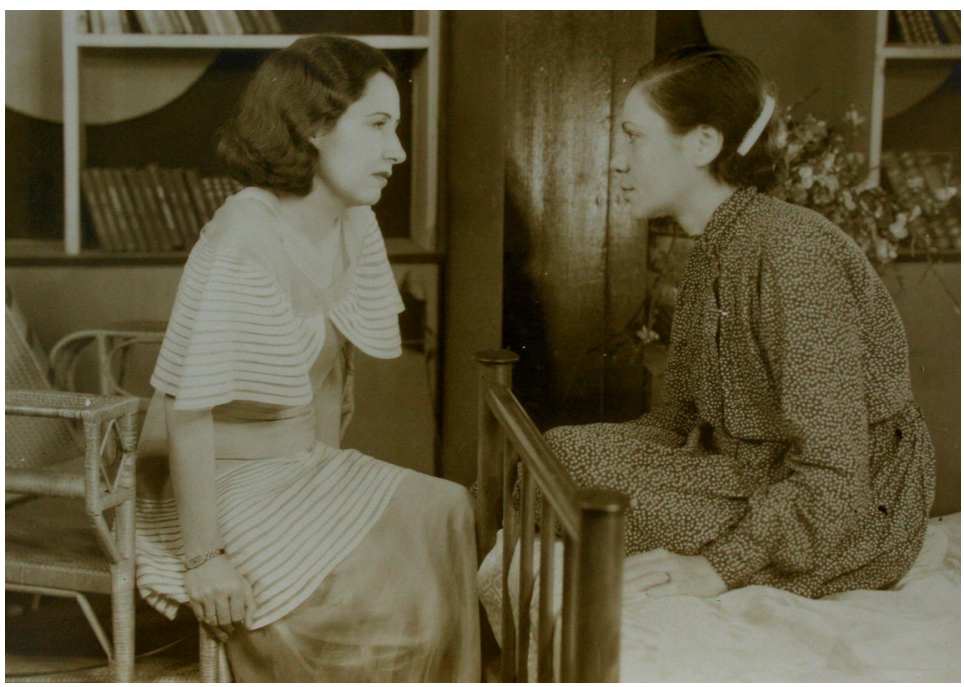

Fonte: AGCRJ.

Segundo as críticas da época, a singularidade de Favela dos meus amores residiria sobretudo em sua abordagem estetizante e poética de um cenário ainda inexplorado pelo cinema brasileiro sonoro de longa-metragem e que, apesar de passar por um processo de valorização cultural devido à popularização do samba, ainda era fortemente estigmatizado socialmente. Não obstante essa estigmatização, é também a partir dos anos 1920 que o samba se tornou preponderante nos morros, atraindo outro olhar para o que ali se produzia (OLIVEIRA e MARCIER, 1998). No referido filme, os personagens construíam um cabaré na favela justamente para atender a turistas e moradores do Rio “à cata de sensações novas" (FREIRE, 2011, p. 269).

Muitos cronistas destacaram o talento de Mauro como diretor, apontando como ponto alto do filme sua cena final, quando é anunciada a morte do sambista tuberculoso Nonô (Armando Louzada), inspirado no célebre compositor Sinhô. Para uma visão mais distanciada, porém, é interessante citar uma crítica posterior, assinada por Jonald, pseudônimo de Oswaldo Marques de Oliveira, quando do relançamento de Favela dos meus amores cerca de 10 anos depois de sua estreia. O crítico 
destacava o talento de Mauro para o "cinema plástico", mas deixava claro que o maior destaque era a célebre cena do cortejo fúnebre de Nonô, enquanto o filme em si seria apenas um "misto de musical e comédia" (JONALD, 1947). De acordo com o crítico, a encenação dessa cena final se aproximaria do "estilo do cinema russo", se referindo aí não apenas ao uso mais elaborado da montagem, mas à provável filmagem em locações autênticas e marcadas pela pobreza real do cenário e da população negra filmada in loco. O próprio estilo do texto parece mimetizar o suposto estilo da sequência do filme, com planos descritivos articulados por sua combinação: "A série de indivíduos de cor quando do velório de Nonô colocados em vários planos diferentes. A saída do caixão. Os passos na rua. A movimentação das sombras. O caixão, exposto no alto do morro, ao lado da igrejinha" (JONALD, 1947). Por outro lado, a mesma igrejinha no alto do morro onde ocorria o funeral de Nonô era também o principal pano de fundo para o amor dos personagens de Mayer e Carmen. Aliás, a publicidade do filme, como o próprio título dava a entender, destacava a favela principalmente como cenário exótico e inusitado para um romance entre dois personagens brancos, originalmente vindos do asfalto, cujos destinos se cruzavam no morro por acaso.

Apesar de ser apenas uma sequência, a sempre citada cena do enterro de Nonô parece ter se tornado um trecho icônico na representação da favela no cinema brasileiro da primeira metade do século XX, a ponto de percebermos a evidente citação feita à cena no número musical "Lata d'água" do filme Tudo azul (Moacyr Fenelon, 1951), parcialmente filmado em locações reais no morro da Providência. Em ambos os filmes, vemos o mesmo oratório no alto do morro com enquadramentos muito semelhantes (Figuras 4 e 5 ). ${ }^{6}$

6 Napolitano (2009) localiza a cena de Favela dos meus amores no morro da Providência, enquanto Melo (2017) transcreve crítica indicando que a sequência de Tudo azul foi filmada no morro do Pinto. A proximidade das duas favelas, ambas na região portuária, explica a confusão. Segundo Valladares (2005), a ocupação do morro da Providência, datada de 1897, teria concentrado todas as atenções após a violenta campanha contra os cortiços, sendo comumente evocada como a primeira favela da cidade. 
Figura 4 - Favela dos meus amores.

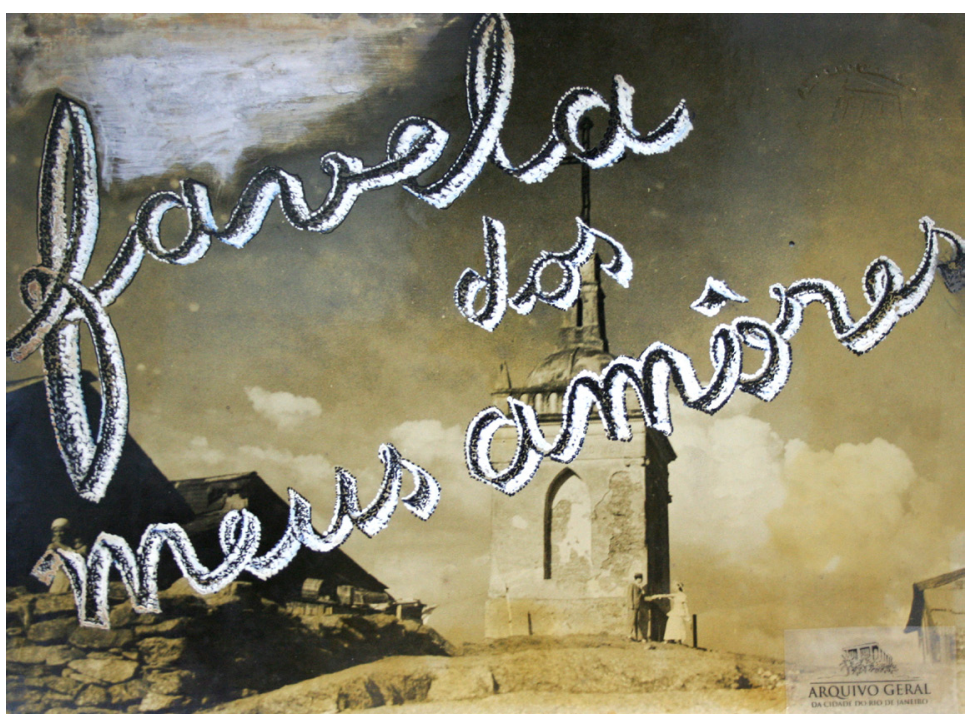

Fonte: AGCRJ.

Figura 5 - Frame do filme Tudo azul.

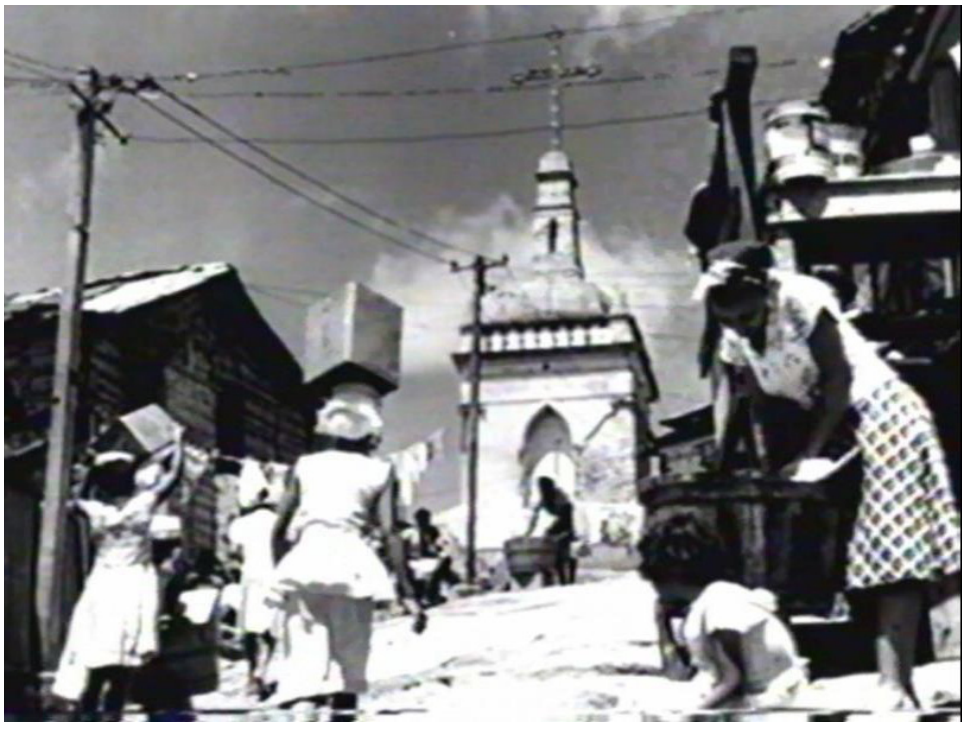

Fonte: Reprodução. 
Entretanto, podemos afirmar que uma imagem mais realista da favela como cenário, colocando em cena a pobreza dos barracões e a população negra que majoritariamente habitava esses espaços, ocorria apenas pontualmente em Favela dos meus amores, mesmo assim se constituindo em exceção no contexto cinematográfico da década de 1930. A constante era a representação romantizada e estilizada da favela como uma espécie de "berço do samba”, em referência não à origem do gênero musical, mas aos espaços onde ele germinou e se popularizou. Como nos mostram Hermano Vianna (1995) e Carlos Sandroni (2001), o samba urbano carioca passava, justamente nesse período, por um processo de transformação em símbolo de identidade nacional, num esforço de legitimação que implicava negociação e, eventualmente, idealização ou apropriação de suas características e origens populares.

Assim, a tendência principal nos filmes musicais brasileiros era a presença da favela como cenário recriado em estúdio para números musicais de samba interpretados, na maioria das vezes, por cantores e cantoras brancos para plateias igualmente brancas. Podemos citar vários exemplos de filmes que, felizmente, têm cópias preservadas. É o que vemos no número musical "Molha o pano", composição de Getúlio Marinho e Cândido Vasconcellos interpretada por Aurora Miranda em Alô, alô, carnaval (Adhemar Gonzaga e Wallace Downey, 1936). Como no restante do filme, o cenário da favela também é insinuado através de desenhos que ocupam o fundo do palco - assinados pelo elegante traço de J. Carlos -, criando o espaço imaginário para o samba interpretado por uma cantora branca (a irmã de Carmen Miranda), mesmo que vestida como um malandro de morro. E em números apresentados para plateias ricas e brancas, trajadas a rigor, como era o cassino Mosca Azul de Alô, alô, carnaval, criado à semelhança do célebre Cassino da Urca. A mesma prática se dava na favela reproduzida no set de filmagem do número musical "Luar do morro" (Walfrido Silva e Sinval Silva), interpretado por Odete Amaral como parte do filme dentro do filme de O samba da vida (Luiz de Barros, 1937). Nessa favela de estúdio, aliás, era recriada toda uma iconografia supostamente representativa de certo imaginário sobre 
o morro carioca, com o coro de cabrochas, malandros de camisa listrada, baianas vendendo doces e botequim servindo cachaça.

Além dessas duas produções da Cinédia, se prosseguirmos pelas décadas seguintes, podemos citar ainda a primeira chanchada dos estúdios da Atlântida, Tristezas não pagam dívidas (Ruy Costa, 1944). Nesse filme, novamente temos a decoração de barracos de madeira e da lua no céu a emoldurar a interpretação de Silvio Caldas para "Laura" (Ataulfo Alves) no palco da luxuosa boate para onde vão os personagens de Ítala Ferreira, Jayme Costa e Oscarito, dispostos a gastar na folia do Carnaval todo o dinheiro oriundo de uma herança. Podemos chegar até outra produção da mesma Atlântida, mas já sob o controle de Luiz Severiano Ribeiro: Vamos com calma (Carlos Manga, 1956), em que um conjunto de músicos e sambistas de uma escola de samba interpreta "Fala, mulato" (Alcebíades Nogueira e Ataulfo Alves) em meio a barracões e bananeiras cenográficas como atração para os convidados de uma festa de grã-finos.

Em todos esses filmes, a favela era imaginada como reduto do samba e, portanto, como cenário apropriado para os números musicais, talvez porque ela também já fosse, nesse período, tema recorrente em grande parte das letras de sambas (OLIVEIRA e MARCIER, 1998). Porém, a favela virava mera decoração nos palcos de elegantes boates ou luxuosos salões em que sambas eram cantados em meio a barracos falsos, bananeiras cenográficas e um luar artificial. E os moradores das favelas, também tratados como elementos decorativos desse cenário, apareciam apenas como coro a acompanhar cantores e bailarinos vestidos de malandros, cabrochas ou lavadeiras a se apresentar para uma distinta plateia branca trajada de smoking e vestidos longos, tal como provavelmente ocorria nos palcos reais da cidade. Cenas filmadas em locações autênticas nas favelas do Rio de Janeiro ocorriam apenas ocasionalmente, como em Berlim na batucada (Luiz de Barros, 1944) ou no já citado Tudo azul - e sempre, igualmente, associadas ao samba. 


\section{A favela e a luta de classes}

O filme que consideramos um marco na mudança da representação das favelas nas chanchadas brasileiras é Depois eu conto (José Carlos Burle, 1956). Nessa comédia musical, a favela entra na trama, deixando de ser um cenário ocasional para números musicais e sendo invocada como território simbólico que evidencia o Rio de Janeiro como uma cidade radicalmente dividida socialmente.

O filme conta a história de Zé da Bomba (Anselmo Duarte), frentista que, durante o dia, trabalha num posto de gasolina no bairro do Engenho de Dentro junto com Veludo (Grande Otelo), namorando a mocinha Sônia Canabrava (Eliana Macedo) e brigando com sua tia, Ofélia Canabrava (Dercy Gonçalves), uma solteirona suburbana. À noite, porém, Zé da Bomba tira o macacão e veste um terno para se passar pelo paulista "quatrocentão" José Pires e Camargo. O vigarista frequenta a luxuosa boate Astral, em Copacabana, desfilando com os carros dos clientes do posto de gasolina e namorando a socialite Marilu Biscainha (Ilka Soares).

Enquanto Zé da Bomba é desmascarado, mas, mesmo assim, consegue ganhar alguma vantagem, Ofélia tenta seguir carreira artística. Descobrindo que seu antigo noivo pobretão, Armindo (Zé Trindade), agora é diretor artístico da boate, ela consegue ser escalada para estrelar um número musical. Mas Ofélia é sabotada pelos diretores da Astral e sua interpretação dramática é ridicularizada pela plateia de grã-finos.

É nesse momento que temos uma virada no filme, quando os outrora desafetos Zé da Bomba e Ofélia resolvem se aliar. Numa reconciliação baseada em solidariedade de classe (e numa oposição compartilhada aos grã-finos que os desprezaram), Zé encontra Ofélia nos bastidores após ela sair do palco humilhada e elogia seu desempenho como atriz. Eles travam um diálogo que merece ser analisado detalhadamente:

Zé: O seu erro é pensar que é atriz dramática, você é uma das maiores caricatas que eu já vi.

Ofélia: A palhaça Bofélia, não é? 
Zé: Outro erro seu. Tanto é artista quem faz chorar como quem faz rir. $\mathrm{E}$ você sabe fazer rir! O que lhe falta é ambiente. [...] Aqui só vale quem tem cartaz ou é estrangeiro.

O diálogo de Depois eu conto claramente ecoa o discurso presente num filme anterior do mesmo diretor, o mais conhecido e estudado Carnaval Atlântida (José Carlos Burle, 1952). Nesse filme-manifesto, conforme análise clássica de João Luiz Vieira (1987), articula-se uma oposição entre cultura popular e cultura de elite, representada no confronto entre a alegria e vivacidade de uma expressão popular autenticamente nacional e a pretensão a uma cultura pesada e importada, de uma seriedade postiça, por uma elite intelectual supostamente colonizada. Em ambos os filmes, portanto, percebemos a influência de uma ideologia do nacional popular, geralmente associada apenas ao chamado cinema independente dos anos 1950. ${ }^{7}$ Se em Carnaval Atlântida, tomando o cinema como objeto, o teor nacional popular se pautaria na defesa da chanchada carioca ante as superproduções do cinema industrial paulista, em Depois eu conto, a partir da música e do espetáculo, se expressa na oposição, mais localizada no Rio de Janeiro, entre trabalhadores do subúrbio e grã-finagem da zona Sul.

Continuando o diálogo, Sônia ainda se mostra cética sobre a regeneração de Zé, mas Ofélia, aparentemente convencida de que ela também teria seu valor, questiona o antigo namorado da sobrinha sobre o que se poderia fazer:

Zé: Reagir! Lutar! Vamos montar uma boate nossa, que seja bem nossa, $100 \%$ nossa.

Ofélia: Mas para isso é preciso muito dinheiro [...].

Zé: Nem é preciso gastar muito. Em vez de luxo, originalidade. Você já pensou o que seria levar essa grã-finagem para uma boate no morro, um

7 Galvão e Bernardet (1983, p. 70) analisaram as características desse nacional popular em textos de cineastas ligados ao Partido Comunista Brasileiro do início dos anos 1950: "O filme nacional e popular que se opõe ao filme cosmopolita de uma burguesia aliada ao imperialismo não é apenas diferente, não é apenas popular, mas, para Nelson [Pereira dos Santos], ele é antiburguês". 
barracão mobiliado com bancos, barricas, latas e caixotes? [...] Vamos mostrar o que é uma batucada de agogôs, cuícas, pandeiros, tamborins... Vamos trazer para o palco aquela gente simples do morro, que canta com alma porque tem o samba no coração.

Zé assegura a Ofélia que consegue levar a grã-finagem para o morro com a ajuda de Reneé Dorê (Teófilo de Vasconcelos), famoso colunista social que, na verdade, é Pinga-fogo, seu amigo de infância do subúrbio, quando os dois estudaram juntos numa escola pública e brincavam com outros meninos da favela. Ou seja, seria possível usar os mesmos circuitos de produção (show de boate) e comunicação (colunismo social) já existentes, mas para encenar e divulgar outra produção cultural, verdadeiramente nacional e autêntica.

O plano seguinte a esse diálogo é de uma filmagem feita em locação, mostrando Zé da Bomba na janela de um modesto apartamento ao pé de um morro onde se vê uma favela ao fundo (ao que tudo indica, a Providência) - a primeira que se mostra em Depois eu conto (Figura 6). Essa imagem claramente traduz a estratégia esboçada no diálogo anterior, em que Zé da Bomba e Ofélia assumem os papéis de intermediários entre uma cultura popular autêntica (“a batucada de agogôs, cuícas”) e a elite econômica representada pela grã-finagem da zona Sul. Seriam essas figuras - símbolos de uma possível classe média - aquelas capazes de criar as condições para a expressão de uma cultura popular e, portanto, verdadeiramente nacional.

Na última parte de Depois eu conto, o sucesso da boate Favela é grande, mas os donos da Astral, inconformados com a concorrência, contratam alguns capangas para promoverem um quebra-quebra. Percebendo a cilada, Zé sai para pedir a ajuda de sambistas negros, seus amigos de infância, para virem em sua defesa. Indo além de Carnaval Atlântida, o filme encena uma representação quase literal da luta de classes: mobilizados por esses "intelectuais de classe média”, negros trabalhadores e favelados brigam contra arruaceiros brancos e profissionais a serviço da elite. Mas tudo se resolve com humor e, sobretudo, com música. No final feliz, temos na boate Favela uma apoteose musical de 
caráter totalizante nacionalista: a letra cantada por Eliana, vestida de baiana, diz: "Eu cantei em São Paulo/Eu cantei no Pará/Tomei chimarrão, comi vatapá”.

Figura 6 - Depois eu conto.

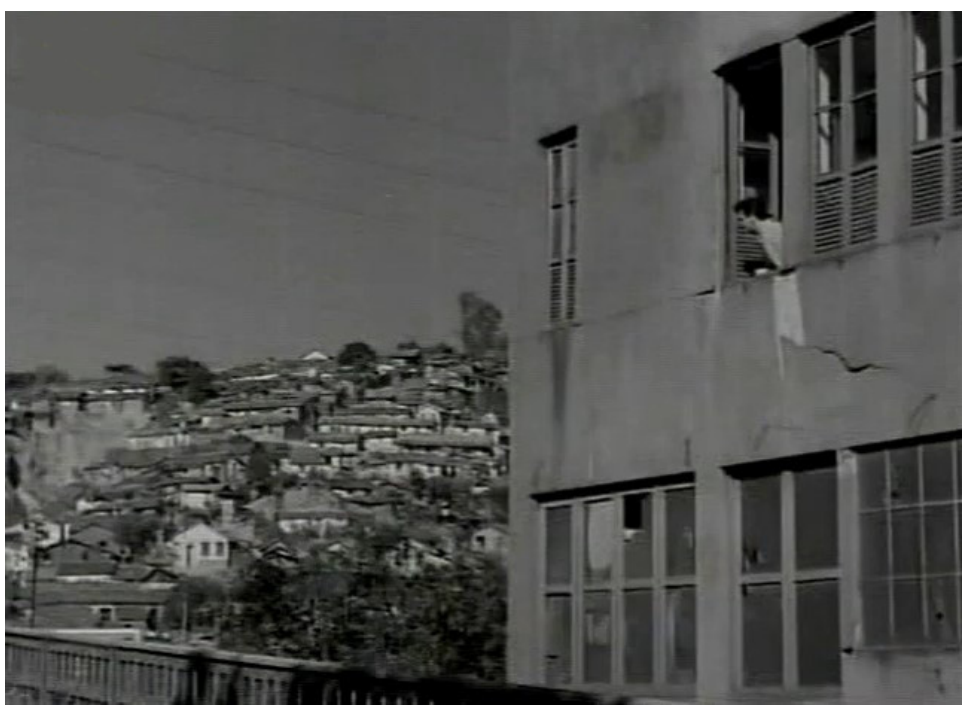

Fonte: Reprodução.

Entre as críticas da época, a de José Sanz, no jornal O Globo, foi a que melhor percebeu, para desagrado do próprio crítico, o discurso ideológico presente em Depois eu conto: "Há, ainda, neste filme, uma grave subversão de valores morais, que o torna parente muito próximo dos conceitos sociais comunistas consubstanciados ultimamente na fita Rio 40 graus, cujo diretor, por sinal, acaba de ser premiado num festival por trás da Cortina de Ferro" (SANZ, 1956). ${ }^{8}$

Apontando em Depois eu conto o maniqueísmo evidente entre personagens de diferentes classes sociais, tal como vemos no filme de estreia de Nelson Pereira dos Santos, o crítico denunciava: "É a tese comunista em sua ampla significação: à burguesia nada se deve perdoar, principalmente

8 O cineasta Nelson Pereira dos Santos tinha viajado à Tchecoslováquia para participar do festival de Karlovy-Vary, em 1956, com Rio 40 graus. 
as qualidades, ao passo que ao proletariado tudo é permitido como autodefesa contra a classe que historicamente o oprime" (SANZ, 1956).

Percebemos que, sob a égide do nacional popular, a luta de classes invadiu as chanchadas com Depois eu conto, ainda que adaptada às convenções do gênero, como o clímax da briga generalizada, o estrelismo branco nos moldes de Hollywood e um final conciliador pautado no nacionalismo cultural. A avaliação satisfeita do próprio Anselmo Duarte (além de ator, corroteirista e coprodutor) também aponta como Depois eu conto era uma chanchada convencional, mas com pretensão a algo de novo: "Este filme deu-nos a experiência de que era possível coexistir o enredo crítico com uma trama popular" (SINGH JR., 1993, p. 61). Mas o que nos interessa especialmente destacar é como as favelas surgem, em Depois eu conto, novamente como berço autêntico do samba, mas num movimento que não é o de levar a favela cenográfica para as boates grã-finas, mas de trazer a plateia grã-fina para uma batucada supostamente autêntica no morro. Cabe à figura de Zé da Bomba o papel que o mesmo Nelson Pereira dos Santos reservaria ao personagem do músico branco de classe média Moacyr (Paulo Goulart) em seu segundo longa-metragem, Rio zona Norte (Nelson Pereira dos Santos, 1958): o de divulgador da verdadeira cultura popular. Em ambos os filmes, aliás, a estrutura da indústria cultural não é realmente questionada, a questão racial é recoberta pela questão nacional e a postura paternalista do intelectual é naturalizada (AUTRAN, 2010).

Depois eu conto, portanto, representa a introdução da favela como símbolo de uma cultura popular autêntica e oprimida nas chanchadas, marcando também o início de uma nova fase no gênero. Deixando de ser um cenário ocasional para números musicais, a favela passa a ser invocada como território simbólico que evidencia a oposição entre o nacional e o estrangeiro, o autêntico e o importado, o povo e a elite. A partir de então, e sob diferentes espectros ideológicos, as chanchadas, como outros filmes brasileiros que não se inscrevem no gênero, vão incorporar cada vez mais a favela, real ou cenográfica, às suas narrativas, 
acompanhando sua consolidação, na década de 1950, como um "problema público" (FREIRE, GONÇALVES e SIMÕES, 2010). ${ }^{9}$

\section{Favelas e Igreja católica}

Presentes na paisagem carioca desde o final do século XIX, assim que descobertas, as favelas logo passaram a ser vistas como problema a ser resolvido, unindo inicialmente aos escritos de jornalistas as vozes de médicos e engenheiros, preocupados com o futuro da cidade e sua população (VALLADARES, 2005). Após a Segunda Guerra Mundial, a retomada do crescimento econômico acelerou a urbanização no Brasil e na América Latina, e o afluxo de migrantes rurais para as cidades também intensificou o crescimento das favelas, tornando mais aguda a questão da moradia para as classes populares. Por outro lado, em seu projeto desenvolvimentista e modernizador, o Rio de Janeiro - então Distrito Federal - precisava combater as favelas na medida em que representavam o atraso e o passado que se pretendia superar.

Antes que o Estado desenvolvesse políticas públicas de grande porte voltadas para essa questão, a Igreja católica já estava presente nas favelas desde os anos 1940, chegando a quase monopolizar as ações nessas localidades na década de 1950 (FREIRE, GONÇALVES e SIMÕES, 2010). ${ }^{10}$ Apesar de desenvolverem modos de intervenção distintos, essas iniciativas católicas expressavam a urgência de se atuar sobre esses espaços e suas populações, ainda que de um ponto de vista moral, criando terreno para que o Estado assumisse para si, na década seguinte, a ação e o controle sobre o problema, implantando uma radical política de remoção de favelas. Somente entre 1962 e 1974, ao longo das administrações

9 Como esses autores, consideramos “problema público" no sentido atribuído pelo sociólogo Joseph Gusfield (1981), ou seja, como uma situação social que passa a ser tema de debates, controvérsias e conflitos no espaço público, requerendo ser tratada pela ação dos poderes públicos, das instituições e/ou dos movimentos sociais.

10 Embora o Código de Obras de 1937 condenasse as favelas, atribuindo à Prefeitura a responsabilidade de extingui-las, substituindo-as por "núcleos de habitação de tipo mínimo", pouco de fato ocorreu até o prefeito Henrique Dodsworth lançar o programa de Parques Proletários Provisórios em 1942. Os três únicos parques proletários construídos nesse período - na Gávea, no Leblon/praia do Pinto e no Caju - acabaram, porém, se tornando permanentes, e os moradores nunca foram reassentados nas áreas das antigas favelas (VALLADARES, 2005). 
dos governadores Carlos Lacerda, Negrão de Lima e Chagas Freitas, 80 favelas foram extintas na cidade, principalmente na zona Sul, deslocando cerca de 140 mil pessoas para as periferias (MELLO et al., 2012).

Entre as diversas chanchadas a terem favelas como cenário a partir da segunda metade dos anos 1950, o filme Vai que é mole (J. B. Tanko, 1960) toca justamente na polêmica das remoções, além de destacar a forte presença da Igreja católica. Sua história começa com a libertação de Mácio (Ankito), Brancura (Grande Otelo) e Bolinha (Jô Soares), que retornam ao seu barraco no morro após cumprirem pena em um presídio. No fundo "ladrões de bom coração", eles contam com a vigilância do vigário para se manterem na linha. Interpretado por Renato Restier, ator que alternou papéis dramáticos e cômicos em inúmeras chanchadas, o vigário da vizinhança da favela é representado como um religioso simpático e, sobretudo, moderno, que não se furta a jogar bola com os meninos do morro ou roubar uma bicicleta numa situação de emergência. Em uma cena de Vai que é mole, o vigário visita a mansão do comendador Ferreira (Armando Ferreira) para pedir doação para a igreja, sendo travado o seguinte diálogo:

Comendador: Eu cá tenho os meus princípios. Acho que primeiro devem acabar com as favelas.

Vigário: É, tem razão. Aquela pobre gente precisa mesmo de...

Comendador (interrompendo): Principalmente por causa dos turistas. É, por que com aquela porção de barracos...

Vigário: Ué. E é só por isso?

Comendador: Nos dias de corrida do jóquei, os automóveis de pessoas de posição têm que passar pela Lagoa. Até me dá náuseas.

Vigário: E o senhor está contribuindo para acabar com as favelas?

Comendador: A gente também não pode fazer tudo! A vida está pela hora da morte. Imagina o reverendo que uma dose de uísque está custando 250 cruzeiros! 
Chama atenção no filme o diálogo sobre as favelas, um tema (naquele momento) atual e polêmico, servindo ainda para reforçar o caráter dos personagens. Afinal, a cena confirmava o comendador como um personagem sovina e arrogante, seguindo o frequente estereótipo dos milionários egoístas e frios. Com seu forte sotaque lusitano, o personagem interpretado por Armando Ferreira se alinhava mais particularmente à tradição chanchadesca da caricatura negativa do português rico e avarento, usualmente comerciante, na linhagem de tipos rotineiramente interpretados no teatro e no cinema por atores como Oscar Soares e Manoel Pêra. Por outro lado, a cena também ressaltava o bom senso e a boa índole do vigário de Restier, cujas ponderações se contrapunham à visão elitista e reacionária do comendador sobre a questão da remoção das favelas. A percepção daquele problema social como simples "lepra da estética”, a ser escondida do olhar dos turistas e das pessoas de posição, virava alvo de deboche pela chanchada.

Essa associação entre um simpático e moderno personagem religioso e uma visão mais humanista do "problema das favelas" não seria um caso único, ganhando centralidade numa chanchada posterior, Três colegas de batina (Darcy Evangelista, 1961), que merece uma análise mais detalhada.

\section{“Uma chanchada com toques religiosos"}

Desde suas primeiras imagens, o filme Três colegas de batina constrói visualmente a ideia de uma cidade dividida entre a burguesia da zona Sul e as favelas. Ainda durante os créditos, a câmera enquadra, em plano geral, a torre de uma igreja com o mar da praia ao fundo. Em seguida, num movimento panorâmico de quase $180^{\circ}$, revela, no extremo oposto, a favela do Cantagalo. Na banda sonora escutamos a música tema, composta por Ary Barroso especialmente para o filme, "Assim na terra como no céu”, que também dá o tom da história com sua tonalidade sacra (com coral e órgão) e letra humanista.

Três colegas de batina é estrelado por Eliana, que interpreta Celina, uma moça religiosa e membro da paróquia de Nossa Senhora da Paz, 
em Ipanema, onde os padres Matheus, Jeremias e Rafael (Gilvan, Edinho e João, os músicos do Trio Irakitan), vindos da Bahia, fazem estágio. Celina atua nas obras sociais na favela do Cantagalo lideradas pelo caridoso frei Martinho (Edmundo Maia), que, por suas boas intenções, ganha a colaboração imediata dos três jovens freis.

Na primeira parte de Três colegas de batina, frei Martinho tenta levantar recursos para seu projeto de urbanização da favela (incluindo a construção de posto de saúde e escola no alto do morro), o que o próprio religioso define como uma "revolução social, mas no bom sentido". Essa frase é proferida quando frei Martinho, junto com Celina, vai pedir dinheiro ao seu Machado (o mesmo Armando Ferreira de Vai que é mole). Ele tenta conseguir uma doação do milionário argumentando que suas obras sociais melhorarão as condições de vida dos mais pobres, mas alertando em seguida que isso não implicará nenhuma mudança estrutural da divisão das classes sociais. Bem diferente de Depois eu conto, o filme parece assumir conscientemente essa postura sem nenhum traço de ironia, uma vez que a frase sai da boca do velhinho bonzinho que é frei Martinho.

Além de dono do terreno onde estão os barracos, seu Machado é pai de Aluísio (Herval Rossano), rapaz boa-vida que flerta com Celina. Mas como em Vai que é mole, o milionário de Três colegas de batina não se sensibiliza pela situação dos favelados, e, assim, os três padres decidem ajudar frei Martinho a coletar fundos para a obra social. Indo de porta em porta, eles encontram comerciantes e burocratas que também se recusam a ajudar, demonstrando novamente a falta de sensibilidade das elites e do governo. Uma dessas visitas, porém, é especialmente interessante como exemplo de que algumas chanchadas também abordavam temas sociais com um discurso distinto de filmes contemporâneos alinhados a um espectro ideológico de esquerda. Em Três colegas de batina, ao tocar a porta de um apartamento, o padre Jeremias (Edinho) é atendido por um personagem ítalo-brasileiro (Zeloni), a quem pede contribuição para as obras no morro do Cantagalo que favorecerão as criancinhas da favela. O homem se mostra desinteressado - "eu não 
moro no morro, não tenho crianças" - e questiona se o religioso já havia visitado o Vaticano e pedido dinheiro ao papa, que era muito mais rico, ou ainda aos Estados Unidos.

É preciso um pouco de atenção para perceber, ao fundo do cenário do apartamento, o símbolo da foice e do martelo na parede, que evidencia ainda mais a crítica aos comunistas (Figura 7). Jogando a culpa de todos os males do mundo no odioso "imperialismo norte-americano", o ridicularizado personagem comunista, como os demais procurados pelos freis, também não faz nada pelos mais pobres, demonstrando sua hipocrisia e egoísmo. Situação bem diferente dos religiosos católicos, que são mostrados literalmente botando a mão na massa nas obras sociais da favela (ensinando na escola, levantando um muro de tijolos etc.), em cenas filmadas no morro do Cantagalo, ainda que com uma visão paternalista e moralizante dos favelados, vistos como "carentes de auxílio, compreensão e amor" (Figura 8).

Figura 7 - Três colegas de batina.

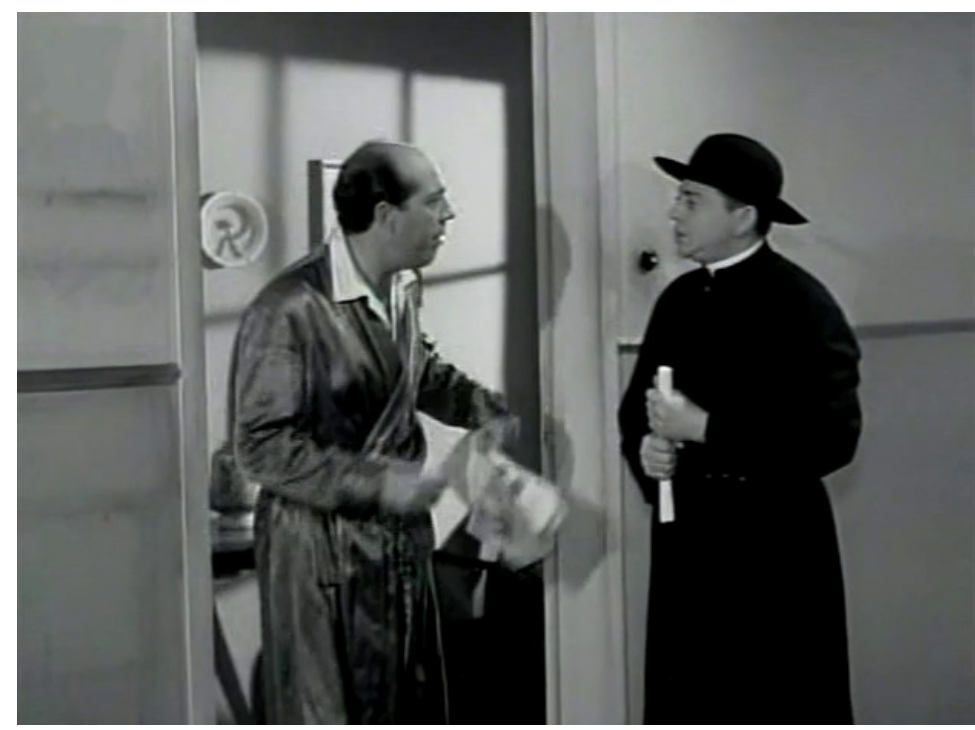

Fonte: Reprodução. 
Figura 8 - Três colegas de batina.

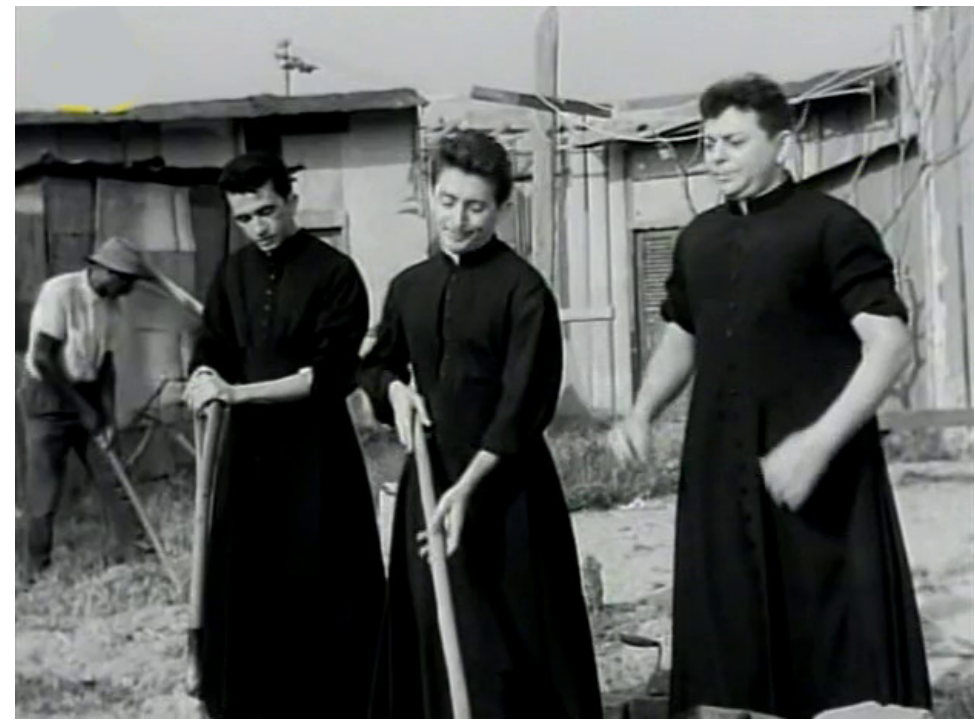

Fonte: Reprodução.

Curioso lembrar que uma das justificativas para as ações da Igreja católica nas favelas nos anos 1950, em particular da Fundação Leão XIII, foi impedir o crescimento da influência do Partido Comunista Brasileiro (PCB) nesses espaços. Cabe mencionar que o PCB foi o quarto partido mais votado nas eleições de 1945 e que muitos de seus vereadores atuavam nas favelas até o partido ser posto na ilegalidade, em 1947, mesmo ano de criação da Fundação Leão XIII. Não por acaso, o lema que preconizava as ações dessa associação católica era: "É necessário subir o morro antes que de lá desçam os comunistas” (SAGMACS, 1960).

Essa preocupação era justificada se pensarmos, por exemplo, em filmes cujas equipes, integradas por jovens intelectuais de esquerda, incluindo membros do PCB, subiam a favela para traçar um retrato crítico da realidade social brasileira, tais como Rio 40 graus (Nelson Pereira dos Santos, 1955) ou Cinco vezes favela (Carlos Diegues, Joaquim Pedro de Andrade, Leon Hirszman, Miguel Borges e Marcos Farias, 1962). Trata-se de obras que defendem mudanças estruturais na sociedade como solução para a desigualdade social e econômica. Nesses filmes, 
um ideário de futuro é baseado na solidariedade de classe por parte dos trabalhadores e na oposição, inclusive moral, entre elite e proletariado. Já Três colegas de batina, uma chanchada alinhada à perspectiva da Igreja católica, propunha soluções paternalistas para os problemas dos mais pobres a partir da perspectiva de um humanismo cristão sustentado na caridade e na contribuição voluntária - isto é, através de alternativas individuais baseadas em escolhas morais. Isso fica claro através da redenção final do personagem de Aluísio, filho do capitalista, que ocorre através do clichê do amor que redime - no caso, por Celina. Sem esquecer de seu tom anticomunista, percebemos que, em Três colegas de batina, a união final dos dois personagens - o galã e a mocinha brancos, jovens e bem-educados - celebra uma possibilidade de projeto futuro, unindo Igreja católica e uma burguesia nacionalista mais humanitária.

Ainda assim, em que pese suas diferenças, em comum entre os mais conhecidos filmes identificados com o Cinema Novo e chanchadas como Depois eu conto ou Três colegas de batina, notamos a presença da favela como ícone de uma sociedade injusta e reveladora do abismo social presente no Rio de Janeiro.

\section{Considerações finais}

Neste artigo, abordamos a representação das favelas cariocas em chanchadas dos anos 1930 a meados dos anos 1950, destacando a constante reprodução estilizada da favela em estúdio como cenário para números musicais de samba encenados em boates e salões luxuosos. Sendo ou não uma exceção, o filme Favela dos meus amores certamente confirmava a regra.

Identificamos uma mudança nessa tradição de representação a partir do filme Depois eu conto, no qual a favela figura como um dos mais importantes problemas urbanos e políticos da capital, ganhando relevância na trama como um símbolo da desigualdade social do Rio de Janeiro. Destacamos como as chanchadas passam a dialogar diretamente com o contexto de crescente politização e polarização da época, enfatizando como alguns filmes do gênero lidam particularmente com 
a relação entre a Igreja católica e as favelas num momento de crescentes e calorosas discussões sobre políticas de remoção desses assentamentos populares por parte do Estado.

Nesse sentido, analisamos em especial o filme Três colegas de batina, no qual a favela tem centralidade como tema e cenário. Nessa chanchada, em que personagens ligados à Igreja católica assumem o papel de protagonistas, notamos um discurso sobre as favelas radicalmente diferente daquele adotado por filmes contemporâneos identificados com o Cinema Novo. Discutindo as chanchadas, evidenciamos como o tratamento das favelas pelo cinema brasileiro tem uma variedade de discursos, inclusive de viés anticomunista e conservador. Concluímos, portanto, que as favelas eram um assunto tão candente na passagem para os anos 1960 que nem as comédias musicais brasileiras - consideradas pela crítica da época como um mero entretenimento alienado e alienante - deixaram de abordar e discutir.

\section{Referências}

AUTRAN, A. Do rádio à televisão: o personagem negro em dois filmes brasileiros. In: ENCONTRO DA COMPÓS, 19, 2010, Rio de Janeiro. Anais... Rio de Janeiro, 2010.

BENTES, I. Sertões e favelas no cinema brasileiro contemporâneo. In: (Org.). Ecos do cinema: de Lumière ao digital. Rio de Janeiro: UFRJ, 2007. p. 191-224.

FREIRE, L. L.; GONÇALVES, R. S.; SIMÕES, S. S. Uma cruzada do século XX: iniciativas católicas no campo das políticas habitacionais na França e no Brasil. Antropolítica. Revista Contemporânea de Antropologia, Niterói, n. 29, p. 201-223, jul.-dez. 2010.

FREIRE, R. L. Carnaval, mistério e gangsters: o filme policial no Brasil (1915-1951). 2011. 504f. Tese (doutorado em Comunicação) - Instituto de Arte e Comunicação Social, Universidade Federal Fluminense, Niterói, 2011.

. Subúrbios reais, anônimos e perigosos: o Rio de Janeiro em três filmes policiais da década de 1950. In: KUSHNIR, B.; VIEIRA, J. L. (Orgs.). Rio, 450 anos de cinema. Rio de Janeiro: Em Tempo: 2016. p. 79-88. 
GALVÃO, M. R.; BERNARDET, J. C. Cinema: repercussões em caixa de eco ideológica (as ideias de "nacional" e "popular" no pensamento cinematográfico nacional). São Paulo: Brasiliense, 1983.

GUSFIELD, J. The culture of public problems: drinking-driving and the symbolic order. Chicago: University of Chicago Press, 1981.

HEFFNER, H. Os realismos da década de 50. In: FRANCO, G. C. (Org.). Olhares neo-realistas. São Paulo: CCBB, 2007. p. 42-45.

JONALD. Favela dos meus amores. A Noite, Rio de Janeiro, [s. p.], 16 jan. 1947.

MELO, L. A. R. Radio stars on screen: critiques of stardom in Moacyr Fenelon's Tudo Azul (1952). In: BERGFELDER, T.; SHAW, L.; VIEIRA, J. L. (Orgs.). Stars and stardom in Brazilian cinema. Oxford: Berghahn, 2017. p. 144-161.

MELLO, M. A. S. et al. (Orgs.). Favelas cariocas: ontem e hoje. Rio de Janeiro: Garamond, 2012.

NAPOLITANO, M. "O fantasma de um clássico”: recepção e reminiscências de Favela dos Meus Amores (H. Mauro, 1935). Significação, São Paulo, v. 36, n. 32, p. 137-157, 2009.

OLIVEIRA, J.; MARCIER, M. H. A palavra é: favela. In: ZALAR, A.; ALVITO, M. (Orgs.). Um século de favela. Rio de Janeiro: FGV, 1998. p. 61-114.

SAGMACS. Aspectos humanos da favela carioca. Separata de: O Estado de S. Paulo, São Paulo, 13 e 15 abr. 1960.

SANDRONI, C. Feitiço decente: transformações do samba no Rio de Janeiro (1917-1933). Rio de Janeiro: Zahar, 2001.

SANZ, J. Depois eu conto. O Globo, Rio de Janeiro, [s. p.], 14 ago. 1956.

SINGH JR., O. Adeus cinema: vida e obra de Anselmo Duarte, ator e cineasta mais premiado do cinema brasileiro. São Paulo: Masao Ohno, 1993.

STAM, R. Introdução à teoria do cinema. Campinas: Papirus, 2003.

VALLADARES, L. P. A invenção da favela: do mito de origem a favela.com. Rio de Janeiro: FGV, 2005.

VIANNA, H. O mistério do samba. Rio de Janeiro: Zahar, 1995.

VIEIRA, J. L. A chanchada e o cinema carioca (1930-1955). In: RAMOS, F. (Org.). História do cinema brasileiro. São Paulo: Art, 1987. p. 129-187. 


\section{Sobre os autores}

Rafael de Luna Freire - Professor adjunto no Departamento de Cinema e Vídeo e no Programa de Pós-graduação em Cinema e Audiovisual (PPGCine) da Universidade Federal Fluminense (UFF). Coordenador do Laboratório Universitário de Preservação Audiovisual (LUPA-UFF).

Leticia de Luna Freire - Professora adjunta do Departamento de Ciências Sociais e Educação (DCSE) e do Programa de Pós-graduação em Educação, Cultura e Comunicação em Periferias Urbanas (PPGECC-FEBF) da Universidade do Estado do Rio de Janeiro (Uerj). Pesquisadora do Laboratório de Etnografia Metropolitana (LeMetro-IFCS/UFRJ), do Instituto Nacional de Estudos em Administração Institucional de Conflitos (InEAC-UFF) e do Núcleo de Estudos sobre Periferias (Nespe-FEBF/Uerj).

Data de submissão: 23/02/2018

Data de aceite: 09/05/2018 